\begin{tabular}{|c|c|}
\hline \multirow{3}{*}{ 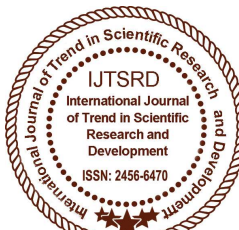 } & International Journal of Trend in Scientific Research and Development (IJTSRD) \\
\hline & International Open Access Journal | www.ijtsrd.com \\
\hline & ISSN No: 2456 - 6470 | Volume - 3 | Issue - 1 | Nov - Dec 2018 \\
\hline
\end{tabular}

\title{
Modeling and Simulation of Cost Effective Sensor Less BLDC Motor Drive for Electric Vehicle Applications
}

\author{
Saravanakumar $\mathbf{M}^{1}$, Adhithya Mannan M.B ${ }^{2}$, Vinothini $\mathbf{R}^{2}$, Gurusamy $\mathbf{M}^{\mathbf{2}}$ \\ ${ }^{1}$ Assistant Professor, ${ }^{2}$ Student \\ Department of EEE, Dr. Mahalingam College of Engineering and Technology, \\ Pollachi, Coimbatore, Tamil Nadu, India
}

\begin{abstract}
This proposed paper is to model and simulate the sensor less control of Brushless DC motor with fourswitch three phase inverter. Here, a new structure of three phase inverter with reduced number of switches (i.e. four-switch) for BLDC drive is introduced to reduce the switching losses that occur in the sixswitch method and eliminate the mechanical commutation. Conventionally used hall sensors for position detection increase the size of the motor and are temperature sensitive since they are mounted inside. So sensor is eliminated and the back emf method is adopted for switching. The zero-crossing point can be detected and it is used to commutate a motor thereby increasing the overall efficiency.
\end{abstract}

KEY WORDS: BLDC, Back EMF, Zero Crossing Detector, Sensorless

\section{INTRODUCTION}

Brushless DC Motors (BLDC) drives are nowadays widely used for various purposes in consumer products and industrial applications. It is attracting much interest due to its high efficiency, high power factor, high torque, simple control, and lower maintenance. An inverter-driven three-phase BLDC motor needs rotor position information to ensure stable operation by synchronizing the phase excitation to the rotor position. This information is generally available by using position sensors. But it is not desirable to use position sensors for applications where reliability is of utmost importance because a sensor failure may cause instability in the control system.

\section{PROBLEMS WITH SENSORED CONTROL AND SIX SWITCH INVERTERS}

Conventional BLDC motor drives are generally implemented via a six-switch three-phase inverter, three Hall Effect position sensors and two current sensors that generate proper signals for current commutation. These sensors have a great number of drawbacks. Position sensor especially Hall sensor increases the size of the motor and are temperature sensitive since they are mounted inside thus limits the operation of the motor in practice. Thus, they increase the cost of the motor and require special mechanical arrangements to be mounted. In addition, they can reduce the system reliability because of their extra components and wiring. In this project, a costeffective position sensor less control for four-switch three-phase BLDC motor drive using a single current sensor is proposed.

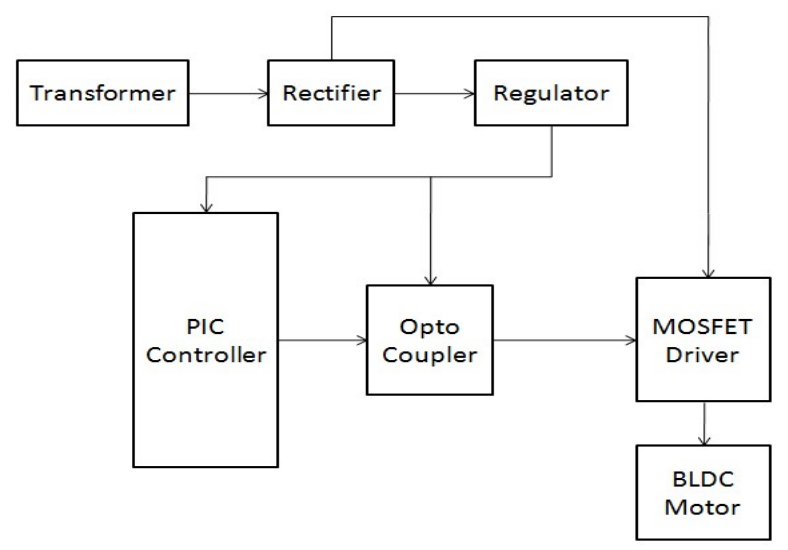

Fig. 1 Block Diagram for Sensorless BLDC 
III. PROPOSED FOUR-SWITCH THREE PHASE INVERTER BRUSHLESS DC MOTOR DRIVE

Usually, Brushless DC motors are excited by Sixswitch three phase inverter, have lot of Commutation Problems and Switch Leg failure and large amount of Switching Losses. The three-phase inverters with only four switches, is striking solution for Six-Switch Inverter to reduce mechanical Strength and Switching Losses. In additional to that with the normal threephase voltage-source inverter with Four switches, the most important descriptions of this proposed converter plays dual role, i) the first is the reduction of Switches and Freewheeling diode count; ii) the second is the reduction of conduction losses.

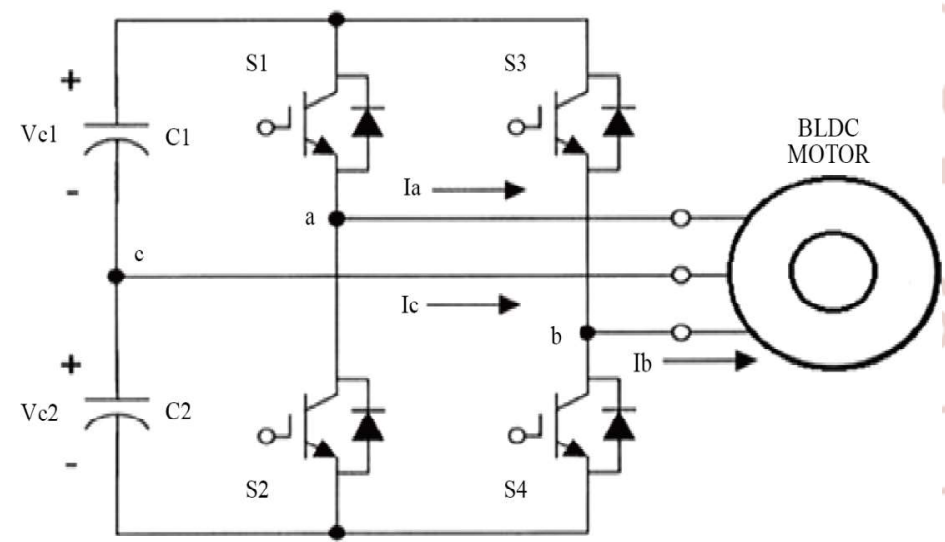

H1g. $L$ Hour Switch tnree phase inverter

In proposed method single phase to three phase converters back end consists of four switches (T1 to T6). In three phase Brushless DC motor, two phases $\mathrm{A}$ and $\mathrm{B}$ are connected to the two legs of the Fourswitch three phase inverter and the third phase $\mathrm{C}$ is connected to the centre point of the capacitor. Phase $\mathrm{C}$ is directly connected to the Brushless DC motor, so the phase $\mathrm{C}$ current is not directly controlled.

$$
\begin{aligned}
& S a+S b+S c=0 \\
& S c=-(S a+S b)
\end{aligned}
$$

Therefore, phase $\mathrm{C}$ indirectly controlled by phase A and phase B. For Brushless DC motors with a trapezoidal back EMF, is required to produce a constant electric torque. The proposed voltage Pulse Width Modulation (PWM) scheme for Four-switch three phase inverter requires six commutation modes which are $(X, 0),(1,0),(1, X),(X, 1),(0,1)$ and $(0, X)$. Here " $\mathrm{X}$ " stands for don't care conditions.
Table 1 Switching sequence of four-switch three phase inverter

\begin{tabular}{|c|c|c|}
\hline Mode & Active Phases & Silent Phases \\
\hline 1 & B and C & A \\
\hline 2 & A and B & C \\
\hline 3 & A and C & B \\
\hline 4 & B and C & A \\
\hline 5 & A and B & C \\
\hline 6 & A and C & B \\
\hline
\end{tabular}

\section{BACK EMF COMPENSATION}

As three-phase Brushless DC motor is motivated with six-step $120^{\circ}$ control process. Therefore, the conduction interval of one phase is $120^{\circ}$. The BackEMF zero-crossing detecting performance is based on only two phases of a Brushless DC Motor. When phase $\mathrm{A}$ and phase $\mathrm{B}$ are connected to the source, phase $\mathrm{C}$ is floating. No current is going through this phase. This conducting interval lasts 60 electrical degrees, which is called commutation step. This is described by the following conditions:

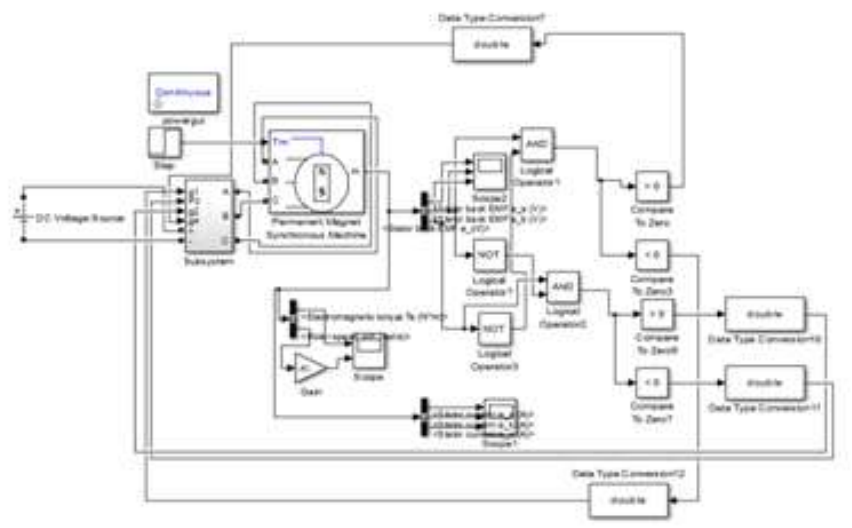

Fig. 3 Simulink Model of Proposed System

If A phase High, B phase Low: which is analysed as general equations.

Normally,

$$
\begin{aligned}
& £ a+£ b+£ c=0 \\
& V a=3 / 2 e w+V d c / 2 \\
& V b=3 / 2 e w+V d c / 2 \\
& V c=3 / 2 e w+V d c / 2
\end{aligned}
$$

In these equations, forward voltage drop of Insulated bipolar transistor and freewheeling diode is ignored. However, in the four-switch converter based on the four-switching operation, the generation of $120^{\circ}$ conducting and a $60^{\circ}$ non-conducting current profile is essentially complicated. That resource the conventional Pulse width modulation schemes 
employed for four-switch induction motor drives cannot be directly applied to Brushless DC motor drives with sensor less. This lead to the improvement of a novel control scheme called Direct Current Controlled Pulse width modulation scheme.

\section{V.RESULTS AND DISCUSION}

The simulation of proposed research four-switch Brushless DC Motor is carried by Simulink and its Simulink model are shown in fig 3.To generate the pulse width modulation signals Subsystems of the proposed converter is shown in fig 4 .

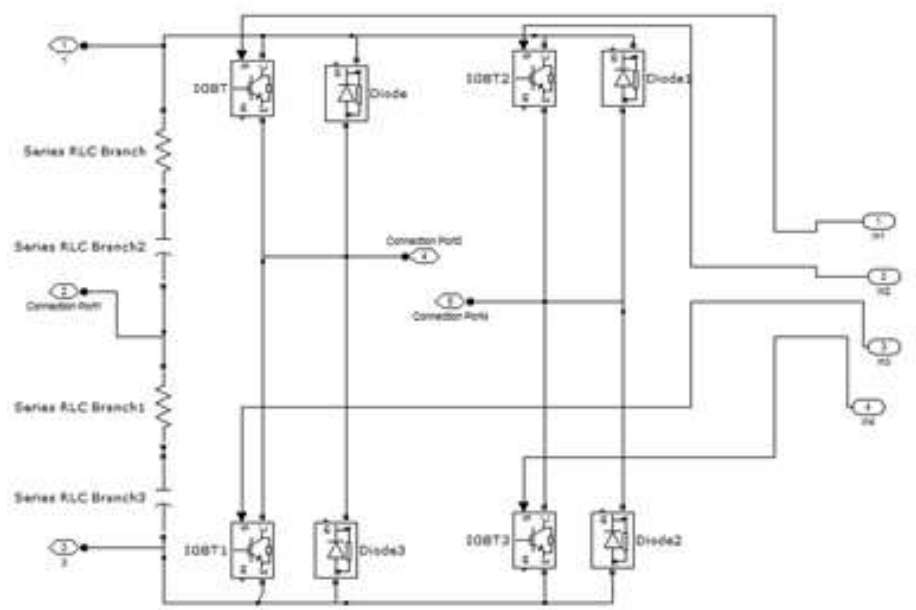

Fig. 4 Subsystem of four switch inverter

The reference speed is set and rotor position sensor speed sensed are given to the controller. If it is equal it is send to the controller or error is generated and rectified and it is given to the controller then the switches generate the Pulses. The Back emf signals generated by the switches from the output of controller are shown in fig 5 .

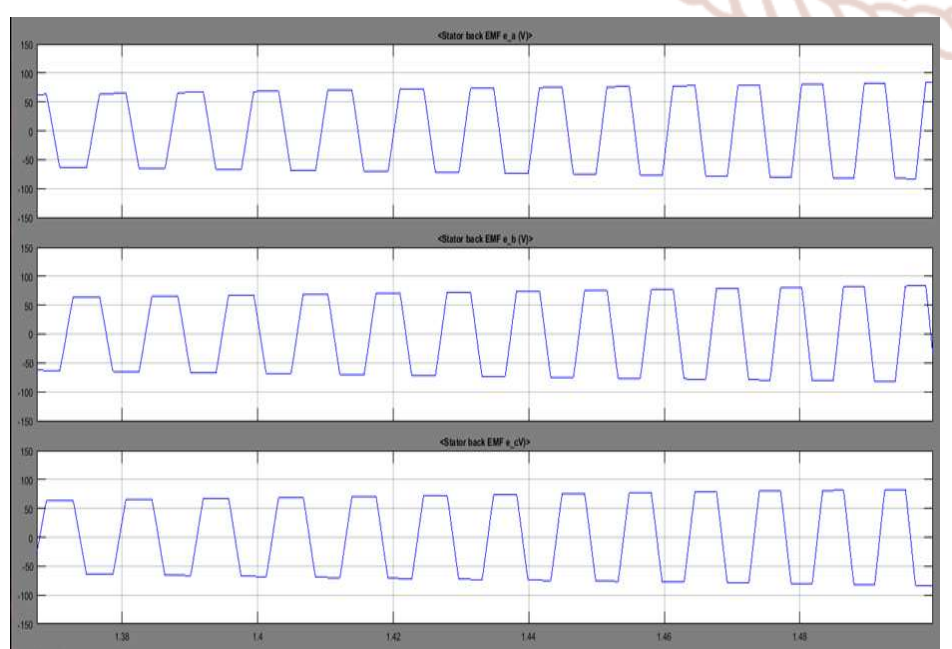

Fig. 5 Back Emf of phase A, B, C
It is carried out by voltage and time period and the results are taken from Simulink environment. The Stator Current signals generated by the switches from the output of controller are shown in fig 6 .

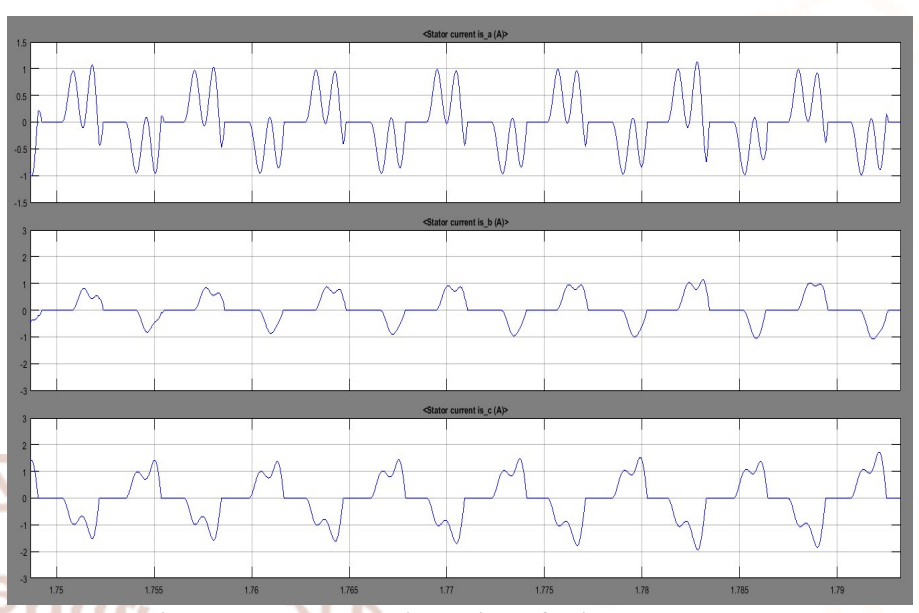

Fig. 6 Current Signals of phase A, B, C

The Torque and Speed curves generated by the switches from the output of controller are shown in fig 7.

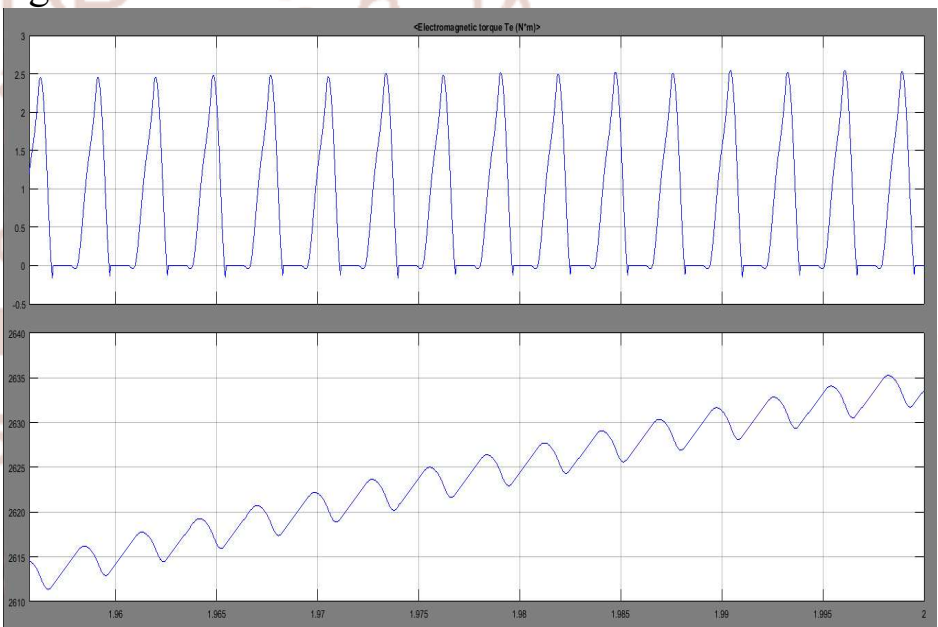

Fig. 7 Torque and Speed Characteristics

\section{CONCLUSION}

Brushless DC drives is preferable for compact, low maintenance and high reliability systems. In order to reduce the mechanical strength it proposed that without sensors and simulations were carried out. The simulation of the brushless DC motor is done using the software MATLAB/SIMULINK. Back EMF, phase voltage, phase current, rotor speed waveforms are analysed for the speed of rotor is $800 \mathrm{rpm}$. In this proposed converter uses less number of insulated bipolar switches which evaluate the difference from conventional converter. The back electromotive force compensating and direct current controlling for brushless DC motor drive was analysed and switch leg failure was avoided. Pulse width modulation 
scheme can eradicate the offset voltage in the back electromotive force signal caused by the voltage drop of the insulated bipolar transistor and also increase system efficiency by reducing the conduction loss is achieved. There are no hall sensors and therefore the system becomes robust, optimized design, higher efficiency and better speed.

\section{References}

1) G. Paranjothi, R.Manikandan "Photovoltaic Based Brushless DC Motor Closed Loop Drive for Electric Vehicle" International Journal of Emerging Trends in Electrical and Electronics (IJETEE - ISSN: 2320-9569) Vol. 10, Issue. 1, Jan-2014.

2) M. Ebadpour, M. B. B. Sharifian, M. R. Feyzi, "A Cost-Effective Position Sensor Less Control for Four-Switch Three-Phase Brushless DC Motor Drives Using Single Current Sensor" International Review of Automatic Control (I.R.E.A.CO.), Vol. 4, N. 3 May 2011.

3) Sathish Kumar Shanmugam, Meenakumari Ramachandran, Krishna Kumar Kanagaraj, Anbarasu Loganathan, "Sensor less Control of Four-SwitchInverter for Brushless DC Motor Drive and Its Simulation", International conference of Circuits and Systems ,May 2016.
4) Abolfazl Halvaei Niasar, Abolfazl Vahedi, Hassan Moghbelli , "Low-cost sensor less control of fourwitch, Brushless DC motor drive with direct backEMF detection" Journal of Zhejiang University of Science (ISSN 1673-565X),2009.

5) Praveen Kumar C, Sobi Soman, "Simulation of Four Quadrant Operation of Sensor less BLDC Motor" Journal of Electrical and Electronics Engineering (IOSR-JEEE), 2015.

6) Bolfazl, H.N., "A Novel Position Sensorless Control of a Four-Switch, Brushless DC Motor Drive without Phase Shifter", IEEE Transactions on Power Electronics, 23, 3079-3087,2008

7) Damodharan, P. and Vasudevan, K., "Sensor Less Brushless DC Motor Drive Based on the ZeroCrossing Detection of Back Electromotive Force (EMF) from the Line Voltage Difference", IEEE Transactions on Energy Conversion, 25, 661-668, 2010

8) Adauria, Y., Patel, A.N., Patel, V. and Patel, J, "Simulation and Analysis of Three Phase Voltage Source Inverter Using Four Semiconductor Switches". Nirma University International Conference on Engineering (NUiCONE),2012. 